\title{
Multicriterial Analyses of Theorethical Models of Innovation Use in Business Practice with a Focus on Open Innovation and Transfer Technology
}

\author{
Pavla MATULOVÁ \\ University of Hradec Králové, Hradec Králové, Czech Republic; pavla.matulova@uhk.cz
}

\begin{abstract}
Innovations are an integral part of corporate strategies and corporate vision, and strategies for their fulfilment are the cornerstone for assessing the innovation capacity of the economy. Innovation is extremely dependent on the availability of knowledge management, and therefore the complexity created by knowledge management tools plays an important role in the successful implementation of innovations. Open innovation is an important concept for any organization or company, no matter how small or large it is. Open innovation involves a collaborative approach, whereby firms integrate external knowledge and expertise into their innovation processes. The aim of this work is to propose an evaluation model of innovation use in business practice with a focus on open innovation. The model will be based on management as a discipline specifying work with explicit and tacit knowledge, as they are the key to innovation. Methodological approaches to modelling include retrospective analysis, qualitative and quantitative surveys in the private sector, multi-criteria decisionmaking and interviews with business innovation managers. The target users of this model are primarily firms in the secondary public sector. The proposed model will both allow the evaluation of quality benefits and contribute to the expansion of the possible methods used in knowledge management.
\end{abstract}

Keywords: multi-criteria decision-making deals; multi-criteria analysis; scoring method open innovation; knowledge management; innovation drivers; evaluation model of innovation

JEL Classification: $\mathrm{O} 30$

\section{Introduction}

Innovation has been defined in various manners throughout literature. Chen et al. (2004) expands on the concept by calling it the entrance of a new set of important elements that inform the production process or influence the production system. Innovation capital is the competence of not only implementing but also organizing research and development aspects of the business, which eventually lead to new products and technology geared at catering to the needs of the customer. It has to do with the fresh product, technology, market, material and more that come into play. Cardinal et al. (2001) explain that the process of innovation covers the physical, technical, and knowledge-oriented activities that are key in creating the development routines for the goods or product in question. Herkema (2003) says that it is the process of developing knowledge that is geared at developing new information and skills, 
aiming to creating viable commercial solutions. IT is a process which holds knowledge in extreme importance because it is further assimilated and shared with the goal of developing knowledge that is fresh and embodies services and goods. Herkema (2003) further explain that it is the process through which an idea or behaviour is brought into an organisation, which previously was alien to the organisation in question. This innovation could be an altogether new service or good or technology that the organisation is willing to adapt or adopt. The change that the firm experiences can be incremental and take place through several steps or be entirely abrupt and come off as a radical modification of processes. Innovation is a process through which change takes place to make room for interventions and discoveries that will augment existing processes and outcomes - this can be true for goods, processes, products, and more (Gloer \& Terziovski, 2004). Radical and incremental modification have been set apart from one another by the authors. Incremental setups have line extensions that impact products that already exist. They do not need substantial modification of existing practices and can often lead to an augmentation of the processes that are already in place. On the other hand, a radical innovation will mean the firm would have to start from scratch because existing competences would be entirely destroyed. It required new skills and practices to be put into place, making older knowledge and skills redundant. This could prove to be a risk for the business because it can be tricky to commercialize a radical change. Nevertheless, a radical switch is thought to be substantially important when it comes to long term success because it brings on new age or more current approaches and helps the company come up to the speed of the market.

“Open innovation is usually contrasted with closed innovation, supposedly its predecessor, where companies generate their own innovation ideas, and then develop, build, market, distribute, service, finance, and support them on their own" (Chesbrough, 2003a, p. 20). On the other hand, the reality is that only a handful of firms go for a fully closed innovation method, and it is imperative that the process of innovation be more open because of the many developments both within and outside the arena of innovation itself.

The aim of this work is to propose an evaluation model of innovation use in business practice with a focus on open innovation. The model will be based on management as a discipline specifying work with explicit and tacit knowledge, as these are the key to innovation.

\section{Theoretical Background}

A simple search through Google Scholar on the subject returned over two million results. Chesbrough's 2003 book on the subject has more than 1,800 citations. Several different disciplines have demonstrated a substantial interest in the subject as well, including sociology, economics, cultural anthropology. When we talk about innovation as a revolution, we mostly see that it is more of an evolutionary process. This is the case with open innovations as well. Chesbrough's publications caused a revolution when they were first released, i.e. Chesbrough (2003a, 2003b, 2003c), helped it become fairly obvious that the crux of them matter dates back by a large margin. Neither using the input of outsiders to improve internal innovation processes, nor searching for outside commercialization opportunities for 
what has been developed internally is new. Most of these activities have been implemented by many companies over many decades. In an extensive literature review, Dahlander and Gann (2010) found many references to concepts such as absorptive capacity, complementary assets and the exploration.

Bures (2006) has split the topic into different parts. Knowledge, according to him, can be tacit, implicit, or explicit. Explicit knowledge is essentially documented and is easy to transfer because of its concrete structure. On the other hand, implicit knowledge, as the name implies, has to do with subjective information which can be converted into something more explicit at any time. Knowledge that is unformulated exists in the minds of the person working on something but can prove difficult to turn into something more concrete or formal.

The typical manner through which tacit knowledge is defined is to put it in comparison with objective knowledge. This can then be communicated from the person who possesses it to another. The method of communication can be symbolic and the receiver then has the same information as the original communication (Winter, 1987). This puts forth that objective knowledge can be deconstructed into two aspects, the first being the objective knowledge's communicability and the second being its possession (Sobol \& Lei, 1994). The authors further argue that "such knowledge is not specific or idiosyncratic to the firm or person possessing $i^{\prime \prime}$ (p. 170). This knowledge can be shared. This definition is widely used throughout the literature to define objective knowledge. However, despite this agreement about what objective knowledge is, there is an abundance of terms used to refer to it: articulated knowledge, articulable knowledge, explicit knowledge (Nonaka, 1991), verbal knowledge and declarative knowledge (Kogut \& Zander,1992). It is important to be aware of these various synonyms because it helps us in deciphering and understanding authors' ideas and arguments. Defining objective knowledge is a way of highlighting what tacit knowledge is not. In what follows, we concentrate on what tacit knowledge is."

Before outlining the nature of tacit knowledge, it should be noted that a large majority of authors that write about tacit knowledge refer to Polanyi $(1962,1966,1976)$ who introduced the concept. Polanyi describes tacit knowledge as follows:" I shall reconsider human knowledge by starting from the fact that we can know more than we can tell' $(1966$, p. 4) or we have a power to know more than we can tell (1976, p. 336). One of the characteristics of tacit knowledge is that it is difficult to write down, to formalize (Nonaka, 1991). People that possess tacit knowledge cannot explain the decision rules that underlie their performance: the aim of a skillful performance is achieved by the observance of a set of rules which are not known as such to the person following them (Polanyi, 1962, p. 49). Another characteristic of tacit knowledge is that it is personal knowledge. Sternberg (1994) and Nonaka (1991) argue that tacit knowledge has a cognitive dimension, in the sense that it is scripted. For them, tacit knowledge consists of mental models that individuals follow in certain situations. These are deeply embedded in the individuals and tend to be taken for granted." Ravetz (1971) suggests that:" tacit knowledge becomes so embedded in the individual that it seems entirely natural. This is a reason why it cannot be expressed and why it is attached to the knower." Another feature of tacit knowledge is that it is practical (Sternberg, 1994) and that it describes a process. If, like some authors (Amit \& Shoemaker, 1993; Grant, 1991; Rao, 1994) we were to 
make a distinction between resources, i.e. inputs into the production process, and capabilities, i.e. processes by which the resources are utilized, rather than use the generic term of resource (meaning both) it would be appropriate to use the term capability rather than resource when referring to tacit knowledge. In this respect, it is similar to know-how (Kogut \& Zander, 1992; Nonaka, 1991). Nonaka (1991) saying that:" know-how may be used as a synonym for tacit knowledge because "tacit knowledge consists partly of technical skills -the kind of informal, hard-to-pin down skills captured in the term know-how. "

\section{Research Methodology}

The aim of this work is to propose an evaluation model of innovation use in business practice with a focus on open innovation. The model will be based on management as a discipline specifying work with explicit and tacit knowledge, as these are the key to innovation. Sub-steps to address the above goal are:

Literature research in relation to models and methodologies of knowledge management and possible methods of innovation evaluation as a basis for determining the framework of the proposed model.

Multi-criteria analysis of variants for the selection of a specific methodological approach to knowledge management.

Table 1. Questions and corresponding research methods

\begin{tabular}{|c|c|}
\hline Question & Methods \\
\hline $\begin{array}{c}\text { I. What key knowledge or knowledge management } \\
\text { approaches can be used for open innovation in business? }\end{array}$ & $\begin{array}{c}\text { Literature research } \\
\text { Multi-criteria analysis } \\
\text { Scoring method } \\
\text { Pool of experts }\end{array}$ \\
\hline $\begin{array}{c}\text { II. What key flows, segments and vectors of innovation } \\
\text { through an appropriate knowledge model influence open } \\
\text { innovation? }\end{array}$ & $\begin{array}{c}\text { Literature research } \\
\text { Correlation to }\end{array}$ \\
& models and methodologies of knowledge \\
& management \\
& Multi-criteria analysis \\
\hline
\end{tabular}

A synthesis of the above-mentioned findings will provide an answer to the question: "Is it possible to design such a model and methodology of effective evaluation of open innovations which would reflect the character of the business environment within the European business territory?" In order to obtain the above-mentioned partial materials for the model creation, quantitative and qualitative research, an analysis of statistical data and expert interviews with key subjects of the innovation strategy of companies were chosen with respect to the used methods.

This work uses the following main methods: synthesis of knowledge, a qualitative research represented by a sophisticated questionnaire and multi-criteria analysis. Qualitative research works with diverse data sources and enables a wide range of methods to be used to find and process data. However, it is more time-consuming and the results are more difficult to interpret (Hendl, 1997). Research takes place in the field, where information and opinions 
are obtained from respondents through direct contact with them. Structured questionnaire interviews are a sophisticated concept of these surveys. Subsequently, the obtained data are classified in a way that allows their statistical analysis.

\subsection{Multi-criteria Analysis}

The theory of multi-criteria decision-making deals with situations where the decision maker evaluates the consequences of the choice according to several criteria. These are quantitative criteria, which are usually expressed in natural scales (referred to also as numerical criteria). Another option are qualitative criteria, when an appropriate scale is introduced, e.g., introducing a classification scale and at the same time defining the direction of better evaluation, i.e., whether the maximum or minimum value is better (falling or rising values) (Skulinova, 2005). If a set of permissible variants (alternatives) is specified implicitly by a set of constraint conditions that the decision alternatives have to meet, it is a vector optimization. If the set of permissible variants is final (given in the form of a final list), it is a complex of evaluation of alternatives or the role of multi-criteria evaluation of variants.

\subsection{Scoring Method}

In this method, it is assumed that the user is able to quantitatively evaluate the importance of the criteria using a certain number of points. With this method, the evaluator assigns each point of each variation to a given criterion a certain number of points from the selected scale, the better the value of the criterion, the greater the score for the variation in question. The number of degrees on the scale depends on the evaluator's resolution, which may not be the same for all criteria. However, the maximum (or minimum) number of points assigned to the best (or worst) value of a criterion must be the same for all criteria. In doing so, it is not excluded that in the case of a partial evaluation according to any criterion, no variant will reach this extreme number of points (it may be a hypothetically determined number).

\subsection{Pool of Experts}

As the selection of criteria and determination of their impact is rather subjective issue, were the criteria consulted with an expert board. The pool of experts included entrepreneurs of important industry fields focusing on innovative entrepreneurship (7experts), experts and consultants from the South Moravian Innovation Centre (4 experts) and the academics (4 experts). The total number of the pool of experts involved into consultation on the multicriteria analysis were 15 members. To the selection of the experts, several principles were applied. It was based on a purpose selection. Experts from the Innovation Centre had to meet several criteria, in particular at least 5 years of consulting experience with a focus on innovation and increase of innovation potential in companies. Furthermore, they had to be currently involved in the process of consulting activities at high-tech companies. Experts coming of commercial field had to meet the focus of the pool of companies on which the research was targeted and actively participate in the implementation of the company innovations. The sampling method was included in the involvement of company experts. 
A method of selecting respondents also referred to as a chain or reference sample, is a type of the selection in which not all units or groups of units have the same chance of being selected for the sample. The selection process begins with individuals who are known to meet the criteria. Subsequently, they are asked to nominate other persons who meet the criteria in the interview and to allow researchers to contact them. These individuals are then interviewed and the process could be repeated. Thus, the sample grows by connecting to social contacts. Because it is difficult to involved experts of these group selected sampling method was very suitable. The academic's background was the field of knowledge management, business and economics. The principle of volunteering was applied to all expert groups. The work with experts was based on individual interview.

The basic information for determining the preferential arrangement of variants is the results of pairwise comparison of these variants with respect to the individual evaluation criteria. Due to its nature, this group of methods is suitable for evaluating variants in a set of qualitative criteria, resp. in situations with a mixed set of criteria where qualitative criteria prevail. The result is not a numerical overall assessment of the variations, but only a breakdown of the set of evaluated variants into several indifferent classes and preferential arrangements of these classes. Variants included in each indifferent class can be considered equivalent to the whole set of criteria.

This group includes methods:

- AGREPREF method

- ELECTRE method class (ELECTRE I., ELECTRE III.)

- PROMETHEE method class (PROMETHEE I., PROMETHEE II.)

- MAPPAC

The above-mentioned methods, based on input information, are used as a tool to support decision-making on the method for assessing the benefits of knowledge management. The specific calculation is performed using MS Excel for manual processing of the scoring method and MCA Scythe for the method of linear partial functions benefit (weighted sum), TOPSIS and ELECTRE I, AGREPREF, MAPPAC and PROMETHE.

\section{Results}

Choice of criteria and impact assessment of individual alternatives in relation to these criteria. The design of the criteria and its weights is a matter of the only expert who will probably also himself calculate and sort the variants by any of the methods of multi-criteria decision making. A group of experts is involved in determining the weighting of criteria and, where appropriate, selecting criteria. The result can then be obtained, for example, by a selected group of experts and selecting a relevant criterion for solving the given decision problem and determining their mutual percentage importance. There is also the amount of the selected group of experts to send questionnaires with draft criteria into which they give their opinion on the importance of each criterion. In this case, the criteria and the determination of their weights is set in frame of work by the author of the present work. 


\subsection{Identifying Alternatives}

Based on literature research and the focus of the work on the possibility of interconnecting the open innovation model with the knowledge management four relevant models of knowledge management were found. The following alternatives were taken:

- SECI model Nonaka - Takeuchi.

- Knowledge spiral.

- "Choo" model.

- Boisot model.

\subsection{Selection of Criteria}

Following criteria were selected:

$\mathrm{C} 1$ : Ability of the model to reflect the specifics of the innovation potential of the company - the most important criterion

C2: Simplicity and Clarity of the Model

C3: Interconnection of model with literature

C4: Quantitative Result of Model Segments

C5: Model Case Study Availability

\subsection{Decision Matrix}

The following table shows the evaluation of methods by selected criteria. Evaluation of alternatives. A large number of methods have been developed over the years to support decision-making. With their help, the user should be able to select the most appropriate option for solving the problem or obtain a preferential arrangement of the options and on the basis of this to justify their decision. The methods differ from each other in the situations in which they are used, the number of criteria, the methods of calculation and the demands placed on the solver.

Table 2. Assessment Criteria Rating Scales Result - methods TOPSIS, ORESTE, PROMETHE

\begin{tabular}{|c|c|c|c|c|c|c|}
\cline { 2 - 7 } & \multicolumn{2}{c|}{ TOPSIS method } & \multicolumn{2}{c|}{ ORESTE method } & \multicolumn{2}{c|}{ PROMETHE method } \\
\cline { 2 - 7 } & $\begin{array}{c}\text { Distance from nadir } \\
\text { (relative index) }\end{array}$ & ri values & ri values & Order & Net flow & Order \\
\hline Choo & 0.462634 & 50 & 50 & 2 & 0.002583 & 2 \\
\hline Boisot & 0.442539 & 58 & 58 & 4 & 0.002975 & 1 \\
\hline Seci & 0.622606 & 44.50 & 44.50 & 1 & -0.00313 & 4 \\
\hline $\begin{array}{c}\text { Knowledge } \\
\text { intensity }\end{array}$ & 0.368844 & 57.50 & $\begin{array}{c}57.50 \\
\text { ri values }\end{array}$ & 3 & $\begin{array}{c}-0.00243 \\
\text { Net flow }\end{array}$ & $\begin{array}{c}3 \\
\text { Order }\end{array}$ \\
\hline
\end{tabular}

Source: author's own work 


\begin{tabular}{|c|c|c|c|c|c|}
\hline & Choo & Boisot & Seci & $\begin{array}{c}\text { Knowledge } \\
\text { intensity }\end{array}$ & $\begin{array}{c}\text { Effectivity of } \\
\text { alternatives }\end{array}$ \\
\hline Choo & -- & 0 & 0 & 0 & Non effective \\
\hline Boisot & 0 & -- & 0 & 0 & Non effective \\
\hline Seci & 0 & 0 & -- & 1 & Effective \\
\hline Knowledge intensity & 0 & 0 & 0 & -- & Non effective \\
\hline
\end{tabular}

Source: author's own work

The choice of method for evaluating the benefits of knowledge management will be based on cardinal methods. There are three basic approaches to evaluating variants in this way:

- Maximizing benefits.

- Minimizing the distance from a fictitious variation.

- Preference sessions.

\section{Conclusion}

For the overall evaluation of all used methods of multi-criteria evaluation of variants, a clear table is used in which the results of individual methods are captured. The order of advantage of given decision options, determined by one of the methods of multi-criteria evaluation of variants, depends mainly on the weights of individual criteria and on the method used. The decision matrix clearly show that the first order appears in the first order, which is represented by the SECI model.

The proposed process evaluation model of innovation use in business practice with a focus on open innovation based on the SECI model contributes to the development of a theoretical framework in the field of the knowledge management science discipline. Specifically, it is based on a modification of the SECI model and in the planned connection with the Ba model in the context of open innovation. The author's solution clearly demonstrates the possibilities of using the theoretical foundations of the knowledge management science discipline in the areas related to the mapping of innovation potential and determines the extension of the knowledge management area to the aspects of processes in the field of evaluation of the use of innovation. Evaluating the use of innovations and describing the interrelated individual processes as well as organisations is a very complex area of research. This work discusses in detail one of the possible approaches, which is based on the dynamics of knowledge processes in relation to the SECI model. The main benefits of the open innovation model are: simplifying work and saving time for the company, as it only explains its challenge once, and the facilitators take over the tedious job of pre-selection and routine communication with potential partners and get the company's offer through to the relevant partners across the region/country. The individual segments and vectors of innovation can be seen as two forms of tacit and explicit knowledge. Based on the evaluation of the vector of innovation, the potential of a company for open innovation can be measured. So far, the model of tacit and explicit knowledge and its flow have been described on the theoretical level by the SECI model. It is possible to follow up on this work by examining individual segments of innovations and their vectors. Based on the optimization of the 
selection of theoretical models, it is possible to design the model which allows the evaluation of quality benefits and the expansion of the possible methods used in knowledge management. Working in a cohesive manner that leads to strategic innovation management can result in a number of new skilled jobs in several new high-tech firms. Supporting open innovation helps foster a system where there is collaboration and reduced costs when it comes to transaction, augmenting the entrepreneurs' and researchers' comprehension of what innovation is. This helps augment the demand for greater functionality when it comes to research institutes and their internal processes and regulations in terms of collaboration for companies and researchers.

Acknowledgments: This work was supported by the Technology Agency the Czech Republic TL02000066 "Effective knowledge transfer management "and internal specific research "Investments under the Industry 4.0 concept."

\section{References}

Boisot, M. (1999). Knowledge assets: securing competitive advantage in the information economy. Oxford: Oxford University Press.

Bureš, V. (2011). System thinking for managers. Prague: Professional Publishing.

Bureš, V. (2006). Knowledge management and its implementation. In Proceeding of 2 nd International Conference on Web Information Systems and Technologies (pp. 115-118).

Cardinal, L. B., Allessandri, T. M., \& Turner, S. F. (2001). Knowledge codifiability, resources, and science based innovation. Journal of Knowledge Management, 5(2), 195-204. https://doi.org/10.1108/13673270110393266

Cavusgil, S. T., Calantone, R.J., \& Zhao, Y. (2003). Tacit knowledge transfers and firm innovation capability. Journal of Business \& Industrial Marketing, 18(1), 6-21. https://doi.org/10.1108/08858620310458615

Chen, J., Zhaohui, Z., \& Xie, H. Y. (2004). Measuring intellectual capital. Journal of Intellectual Capital, 5(1), 195-212. https://doi.org/10.1108/14691930410513003

Chesbrough, H. (2003a). Open Innovation: The New Imperative for Creating and Profiting from Technology. Boston, MA: Harvard Business School Publishing.

Chesbrough, H. (2003b). The era of open innovation. Sloan Management Review, 44(3), 35-41.

Chesbrough, H. W. (2007). Why companies should have open business models. MIT Sloan Management Review, $48(2), 22-28$.

Chesbrough, H. W., \& Crowther, A. K. (2006). Beyond high-tech: early adopters of Open Innovation in other industries. RED Management, 36(3), 229-236. https://doi.org/10.1111/j.1467-9310.2006.00428.x

Chesbrough, H. (2012). Open innovation: Where we've been and where we're going. Research-Technology Management, 55(4), 20-27.

Dahlander, L., \& Gann, D. M. (2010). How open is innovation? Research Policy, 39(6), 699-709. https://doi.org/10.1016/j.respol.2010.01.013

Herkema, S. (2003). A complex adaptive perspective on learning within innovation projects. The Learning Organisation, 10(6), 340-6. https://doi.org/10.1108/09696470310497177

Kogut, B. \& Zander, U. (1992). Knowledge of the firm, combinative capabilities, and the replication of technology. Organisation Science, 3(3), 383-96. https://doi.org/10.1287/orsc.3.3.383

Nonanka, I. (1991). The knowledge-creating company. Harvard Business Review, 162-171.

Nonaka, I., \& Takeuchi, H. (1995). The knowledge creating company: how Japanese companies create the dynamics of innovation. Oxford: Oxford University Press.

Nonaka, I., \& Konno, N. (1998). The Concept of "Ba": Building a Foundation for Knowledge Creation. California Management Review, 40(3), 40-54. https://doi.org/10.2307/41165942

Novak, J. D., \& Gowin, D. B. (1984). Learning How to Learn. Cambridge: University of Cambridge.

Ravetzs, J. R. (1971). Scientific Knowledge and its Social Problems. Oxford: Clarendon Press

Sobol, L., \& Let, D. (1994). Environment, manufacturing technology and embedded knowledge. International Journal of Human Factors in Manufacturing, 4(2), 167-189. https://doi.org/10.1002/hfm.4530040205 